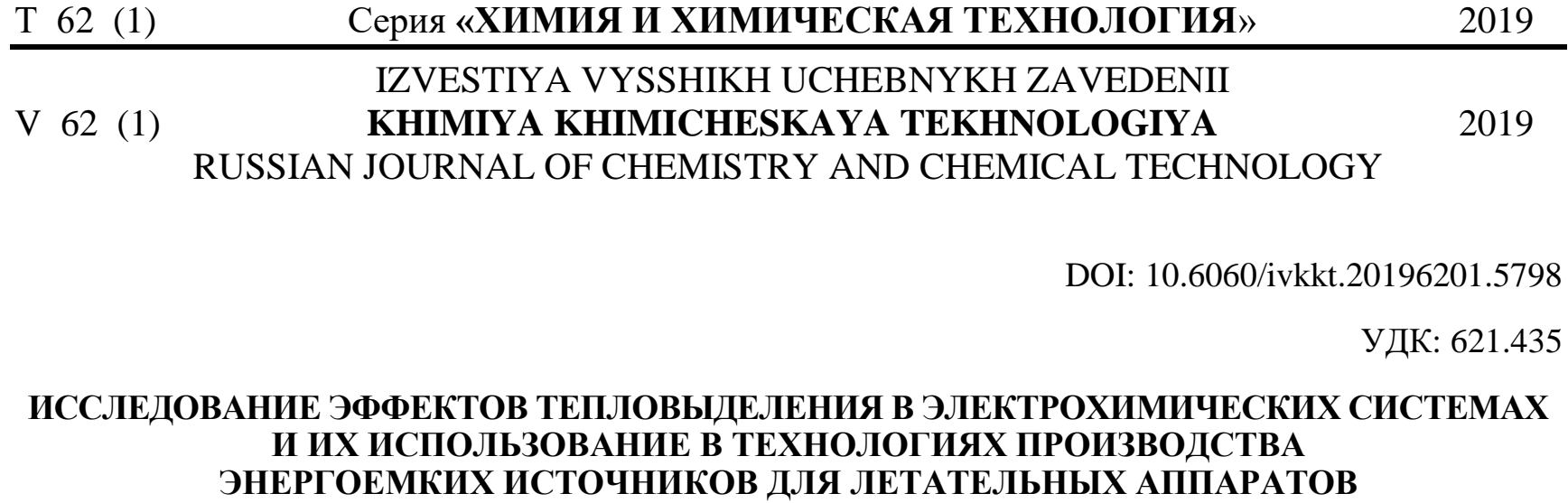

ИЗВЕСТИЯ ВЫСШИХ УЧЕБНЫХ ЗАВЕДЕНИЙ. СерИЯ «ХИМИЯ И ХИМИЧЕСКАЯ ТЕХНОЛОГИЯ» ЭНЕРГОЕМКИХ ИСТОЧНИКОВ ДЛЯ ЛЕТАТЕЛЬНЫХ АППАРАТОВ

Ю.Н. Шалимов, В.И. Парфенюк, В.И. Корольков, И.К. Шуклин, В.И. Кудряш, А.В. Руссу

Юрий Николаевич Шалимов, Игорь Клавдиевич Шуклин

Военный учебный научный центр военно-воздушных сил «Военно-воздушная академия им. проф. Н.Е. Жуковского и Ю.А. Гагарина», ул. Старых Большевиков, 54 «А», Воронеж, Российская Федерация, 394064

E-mail: shalimov_yn@mail.ru

Владимир Иванович Парфенюк*

Институт химии растворов РАН им. Г.А. Крестова, ул. Академическая, 1, Иваново, Российская Федерация, 153045

E-mail: vip@isc-ras.ru*

Владимир Иванович Корольков, Александр Викторович Руссу

Кафедра самолетостроения, Воронежский государственный технический университет, Московский просп., 14, Воронеж, Российская Федерация, 394000

E-mail: korolkov_vi@bk.ru, arussu@mail.ru

Владлен Иванович Кудряш

Воронежский институт МВД РФ, пр-т Патриотов, 53, Воронеж, Российская Федерация, 394065

E-mail: kudrjash_vi@mail

Поиск новых более энергоемких видов топлива для работы силовых энергетических установок летательных аппаратов - важжнейшая задача в авиации. Уникальным топливом, не имеющим аналогов, является водород. В работе предпринята попытка обоснования технологии металлгидридного хранения водорода в электрохимических системах на основе алюминия и его сплавов, как наиболее доступных материалов из ископаемых металлов, поскольку традиционные способы, основанные на применении баллонов и криостатов не эффективны в транспортных системах. Показано, что объемное хранение водорода в пористой структуре металлов с формированием гидридов по дефектам атомных связей максимально пригодно для реализации системы, исключающей избыточное давление и низкие температуры. Пористая структура материала обеспечивает как высокую степень доступности раствора электролита к электроду для накопления гидридов во всем объеме металла, а не только на его поверхности, так и условия для реализации редукционного эффекта, исключающего взрывной характер экстракции водорода. Рассмотрена проблема повыщения температуры в зоне протекания реакций, которая иногда является причиной замедления скорости определенных стадий электрохимического процесса. На примере гальванического хромирования установлено, что рост температуры тормозит процесс восстановления металлического хрома. Поэтому детальный учет тепловых эффектов в электрохимической системе позволяет определить механизм протекания процессов. В работе выявлено, что тепловые эффекты, возникающие на катоде, определяют кинетику процессов восстановления водорода при образовании гидрида. А тепловые эффекты на аноде определяют кинетику форми- 
рования пористой структуры в металле. Авторами предложено использовать принцип действия, связанный с переходом к технологиям объемного хранения водорода в твердофазной системе на основе металлгидридного соединения, для формирования нового класса летательных аппаратов - диапланов.

Ключевые слова: хранение водорода, летательные аппараты на водородном топливе, накопители на основе алюминия, кинетика электрохимических процессов, структура металлов, редукционный эффект в пористых структурах

\title{
INVESTIGATION OF EFFECTS OF HEAT RELEASE IN ELECTROCHEMICAL SYSTEMS AND THEIR USE IN TECHNOLOGIES FOR PRODUCTION OF ENERGY-INTENSIVE SOURCES FOR AIRCRAFT
}

\author{
Yu.N. Shalimov, V.I. Parfenyuk, V.I. Korolkov, I.K. Shuklin, V.I. Kudryash, A.V. Russu
}

Yuri N. Shalimov, Igor K. Shuklin

Military Educational Scientific Center of the Air Force "Military Air Academy named after Prof. N.E. Zhukovsky and Yu.A. Gagarin", Starykh Bolshevikov st., 54 A, Voronezh, 394064, Russia

E-mail: shalimov_yn@mail.ru

Vladimir I. Parfenyuk*

G.A. Krestov Institute of Solution Chemistry, RAS, Academicheskaya st., 1, Ivanovo, 153045, Russia

E-mail: vip@isc-ras.ru*

Vladimir I. Korolkov, Alexander V. Russu

Department of Aircraft Building, Voronezh State Technical University, Moskovskiy ave., 14, Voronezh 394000, Russia

E-mail: korolkov_vi@bk.ru, arussu@mail.ru

Vladlen I. Kudryash

Voronezh Institute of the Ministry of the Interior of the Russian Federation, Patriotov ave., 53, Voronezh, 394065, Russia

E-mail: kudrjash_vi@mail.ru

The search for new, more energy-intensive types of fuel for the operation of the power plants of aircraft is the most important task in aviation. The unique fuel that has no analogues is hydrogen. The paper attempts to substantiate the technology of metal hydride hydrogen storage in electrochemical systems based on aluminum and its alloys as the most affordable materials from fossil metals, since the traditional methods based on the use of cylinders and cryostats are not effective in transport systems. It is shown that the volumetric storage of hydrogen in the porous structure of metals with the formation of hydrides on atomic bond defects is maximally suitable for the implementation of the system, eliminating the excessive pressure and the low temperatures. The porous structure of the material provides both a high degree of availability of the electrolyte solution to the electrode for the accumulation of hydrides in the entire volume of the metal, and not only on its surface, but also the conditions for the realization of the reduction effect that excludes the explosive nature of hydrogen extraction. The problem of increasing the temperature in the reaction zone, which sometimes causes a slowdown in the rate of certain stages of the electrochemical process, is considered. Using the example of galvanic chrome plating, it has been established that an increase in the temperature inhibits the process of the reducing of the metallic chromium. Therefore, the detailed account of the thermal effects in the electrochemical system allows us to determine the mechanism of the processes. The work revealed that the thermal effects arising at the cathode determine the kinetics of the hydrogen reduction processes during the formation of a hydride. And the thermal effects at the anode determine the kinetics of the formation of a porous structure in the metal. The authors proposed to use the principle of action associated with the transition to the technologies of the volumetric storage of hydrogen in a solid-phase system based on a metal hydride compound for the formation of a new class of aircraft - diaplan. 
Key words: hydrogen storage, hydrogen fuel vehicles, aluminum-based storage, kinetics of electrochemical processes, structure of metals, reduction effect in porous structures

Для цитирования:

Шалимов Ю.Н., Парфенюк В.И., Корольков В.И., Шуклин И.К., Кудряш В.И., Руссу А.В. Исследование эффектов тепловыделения в электрохимических системах и их использование в технологиях производства энергоемких источников для летательных аппаратов. Изв. вузов. Химия и хим. технология. 2019. Т. 62. Вып. 1. С. 46-53

For citation:

Shalimov Yu.N., Parfenyuk V.I., Korolkov V.I., Shuklin I.K., Kudryash V.I., Russu A.V. Investigation of effects of heat release in electrochemical systems and their use in technologies for production of energy-intensive sources for aircraft. Izv. Vyssh. Uchebn. Zaved. Khim. Khim. Tekhnol. 2019. V. 62. N 1. P. 46-53

\section{ВВЕДЕНИЕ}

В современных летательных аппаратах работа двигателей основана преимущественно на использовании керосина. Более перспективным вариантом является двигатель на водородном топливе. Проблема создания двигателя на водороде (водород в качестве топлива) связана, в первую очередь, с особенностями его хранения: при большой удельной энергетической емкости у водорода малая плотность. Балонное и криостатное хранение водорода для использования в авиации малоэффективно [1-4]. Наиболее перспективной нам представляется металлгидридная форма хранения водорода. При теоретическом сравнении энергоэффективности равных объемов авиационного топлива и водорода в металлгидридной форме отличие составляет всего лишь $14 \%$ в пользу керосина. Однако факторы теплотворной способности, безопасности, стоимости и экологии указывают на явное преимущество водорода. В настоящее время технология металлгидридной формы хранения водорода интенсивно разрабатывается в российских и зарубежных научных центрах [5-8].

Другим важным критерием при выборе материалов является их аккумулирующая способность, которая должна соответствовать технологической и экономической целесообразности их использования. В наибольшей степени этим требованиям отвечает алюминий: индекс Кларка более $8,2 \%$ (рис. 1), а аккумулирующая способность накапливать водород до 8\% от веса металла.

Технология обработки алюминия обладает рядом особенностей. В частности, раскрытие механизма анодного растворения алюминия трактуется по-разному в работах зарубежных и отечественных авторов. Кроме того, оценка эффективности металлгидридного хранения водорода также определяется неоднозначно. Особенно это касается задач перехода от планарной к $3 \mathrm{D}$ технологии накопления. С этих позиций представляет интерес вопрос о роли электрохимических процессов в технологии производства водородных накопителей. И, в частности, наиболее актуальной является задача изучения влияния локальных тепловых эффектов на электродах на кинетику протекания электрохимических реакций.

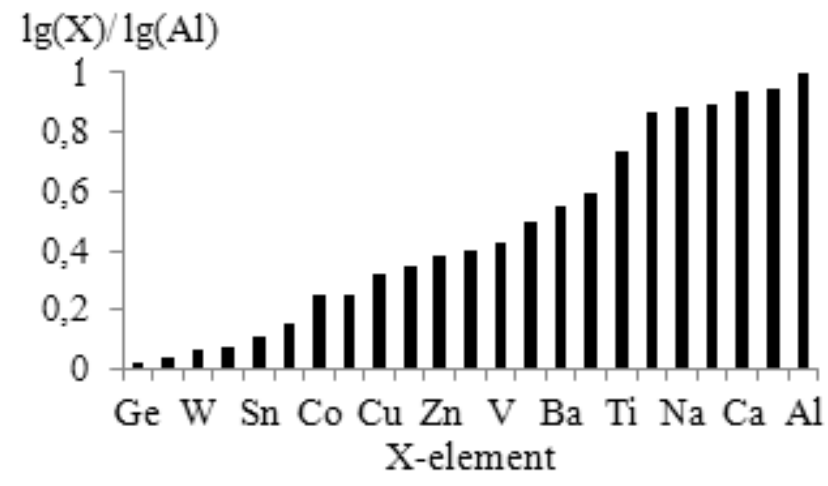

Рис. 1. Диаграмма содержания металлов в земной коре, индексы Кларка [9]

Fig. 1. Diagram of the content of metals in the earth's crust, Clarke numbers [9]

О природе тепловых эффектов электрохимических систем

Анализ электрохимических процессов на электродах и сопутствующих им химических реакций (гидратации, молизации газов, дегидратации, образование гидридов и оксидов) позволил составить обобщенную схему классификации тепловых эффектов, реализация которых наиболее вероятна в электрохимических системах (рис. 2). Классические уравнения электрохимической кинетики, как правило, включают в себя параметр температуры как основной, определяющий кинетику процесса (скорость протекания процесса)

$$
i=k_{1} e^{-\frac{A_{3}}{R T}}
$$

$i$ - плотность катодного тока, Аз - энергия образования зародыша кристалла; $\mathrm{k}_{1}$ - температурный коэффициент предельного тока; R - газовая постоянная; T - абсолютная температура. 


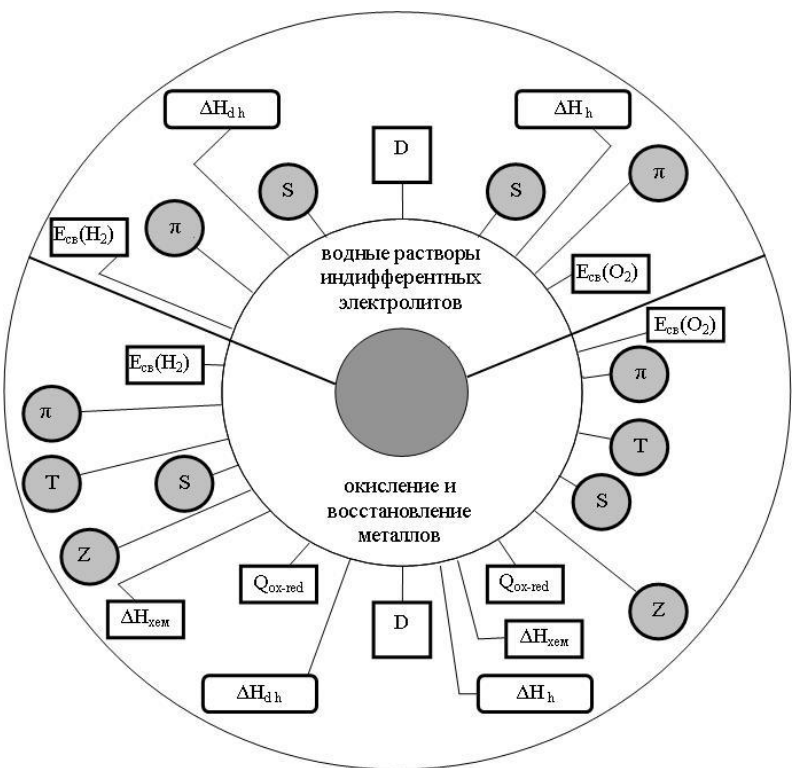

Рис. 2. Тепловые эффекты реакций на электродах и в электролите эффекты $\pi$ - Пельтье, $\mathrm{T}$ - Томсона, $\mathrm{Z}$ - Зеебека, $\mathrm{S}$ - Сорэ; теплоты $\Delta \mathrm{H}_{\mathrm{xeм}}-$ хемосорбции, Qox-red - окислительновосстановительных реакций, $\mathrm{E}_{\mathrm{cB}}\left(\mathrm{H}_{2}\right)$ - молизации $\mathrm{H}_{2}$,

$\mathrm{E}_{\mathrm{c}}\left(\mathrm{O}_{2}\right)$ - молизации $\mathrm{O}_{2}, \Delta \mathrm{H}_{\mathrm{h}}-$ гидратации ионов, $\Delta \mathrm{H}_{\mathrm{dh}}-$ дегидратации ионов; D - тепловой эффект Джоуля [10]

Fig. 2. Thermal effects of reactions on electrodes and in electrolyte $\pi$ - the effect of Peltier, T - Thomson, Z - Seebeck, S - Soret; $\Delta \mathrm{H}_{\mathrm{xeм}}$ - heats of chemisorption, $\mathrm{Q}$ ox-red - oxidation-reduction reactions, $\mathrm{E}_{\mathrm{CB}}\left(\mathrm{H}_{2}\right)-\mathrm{H}_{2}$ molalization, $\mathrm{E}_{\mathrm{cB}}\left(\mathrm{O}_{2}\right)-\mathrm{O}_{2}$ molalization, $\Delta \mathrm{H}_{\mathrm{h}}-$ ion hydration, $\Delta \mathrm{H}_{\mathrm{dh}}$ - ion dehydration; $\mathrm{D}$ - thermal effect of Joule [10]

В приэлектродном слое реализация наиболее высокотемпературной зоны находится на некотором удалении от поверхности электрода в сторону электролита. Температура приэлектродного слоя зависит от основных кинетических параметров: плотности тока, теплопроводности электролита, а также теплофизических свойств твердого металлического электрода. Зона повышенной температуры изменяет свой фронт температур в зависимости от этих параметров. Для изучения динамики этого процесса необходимо проведение дополнительных экспериментальных исследований по измерению характера и структуры этой области повышенной температуры.

Измеренные по различным методикам температурные эффекты при протекании электрохимических реакций на электродах [11-13] позволяют высказать предположения, что в реальных условиях на отдельных участках электрода вероятно существование зон, температура которых на десятки градусов отличается от средней температуры в объеме электролита. Аналитическое выражение для скорости электрохимического процесса должно содержать реальное значение температуры, поскольку это один из главных кинетических параметров.
Если в общем случае повышение температуры электролита увеличивает скорость реакции и оказывает положительное влияние на протекание электродных процессов, то вместе с тем известны примеры электрохимических технологий, в которых наблюдается торможение процесса. Подтверждением этого факта является установленная нами взаимосвязь между температурой электролита и выходом по току хрома. Результаты этих исследований приведены на рис. 3.

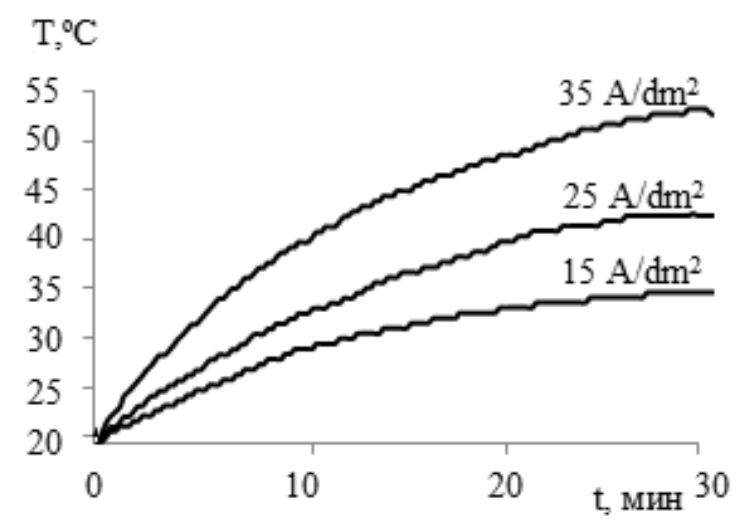

a

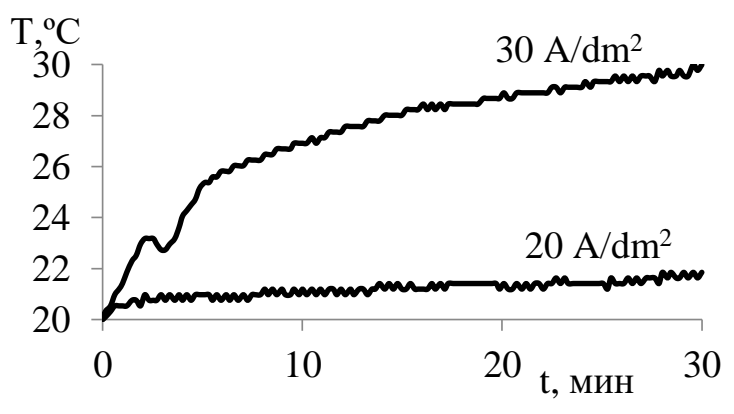

б

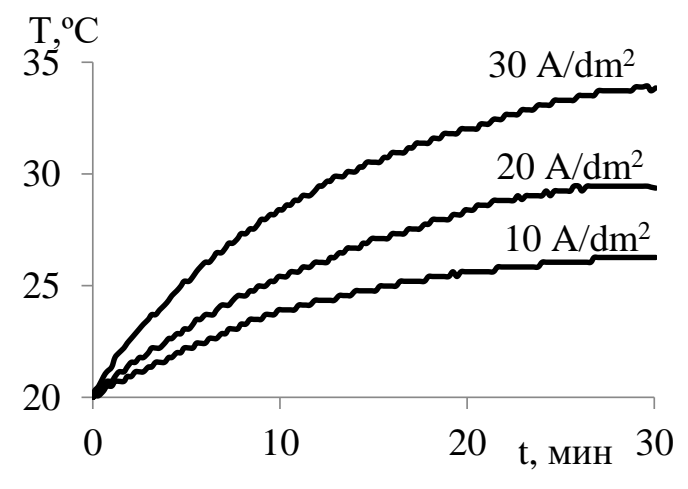

B

Рис. 3. Электротермограммы прикатодного слоя, полученные в электролитах хромирования [14]: a - сульфатные электролиты, б - стандартные электролиты, в - перхлоратные электролиты

Fig. 3. Electrothermograms of the near-cathode layer, obtained in electrolytes of chrome plating [14]: a-sulphate electrolytes, 6 -standard electrolytes, в -perchlorate electrolytes 
На основании классификационной схемы для приведенных на рис. 3 электротермограмм можно составить уравнение теплового баланса:

$$
\begin{aligned}
& Q=Q_{\text {Дж }}+Q_{\text {мол. } \mathrm{H}_{2}}+Q_{\text {мол.О }}+ \\
& +Q_{\text {дегид. } \mathrm{H}_{3} \mathrm{O}}+Q_{\text {рки }}+Q_{C r-H}+ \\
& +Q_{\text {Cr }_{2} \mathrm{O}_{3}}+Q_{\text {хем. }}+Q_{\mathrm{Cr}^{n+} \rightarrow \mathrm{Cr}^{0}},
\end{aligned}
$$

где $Q_{\text {Дж }}-$ джоулевы потери в электролите, $Q_{\text {мол. }{ }_{2}}, Q_{\text {мол.О }}-$ теплоты молизации газов на электродах, $Q_{\text {дешдр. } H_{3} O}$ - теплота дегидратации иона гидроксония, $Q_{\text {рки }}$ - теплота разрушения комплексного иона, $Q_{\mathrm{Cr}-\mathrm{H}}$ - теплота образования гидридов хрома, $Q_{\mathrm{Cr}_{2} \mathrm{O}_{3}}$ - теплота образования оксидов, $Q_{\text {хем }}$ - теплота хемосорбции, $Q_{C r^{n+} \rightarrow C r^{0}}-$ теплота образования атомарного хрома.

Кроме того, следует учесть, что некоторые процессы, например восстановление металлического хрома, могут протекать в несколько стадий. Например,

$$
\mathrm{Cr}^{3+}+e \rightarrow \mathrm{Cr}^{2+}, \mathrm{Cr}^{2+}+2 e \rightarrow \mathrm{Cr}^{0}
$$

Величина тепловых потерь в электролите (джоулевы потери) не только зависит от электропроводности электролита и величины межэлектродного расстояния, но и от характера распределения силовых линий тока в общем объеме электролита. В нашем случае наименьшей электропроводностью характеризуются сульфатные электролиты, поэтому максимальный вклад джоулевых потерь в общий тепловой баланс реализуется именно в этой электрохимической системе [15-18].

Теплоты молизации газов водорода, кислорода и других компонентов определяются количественно энергией связи соответствующих молекул и аналитически могут быть вычислены по известным уравнениям Фарадея, например:

$$
Q_{\text {мол. } \mathrm{H}_{2}}=\frac{V_{\mathrm{H}_{2}}}{11200} \cdot \frac{I t A_{\mathrm{H}_{2}}}{96500} \cdot 103,3 \text { ккал }
$$

где $V_{H_{2}}$ - объем выделяющегося водорода, который зависит от плотности тока, $I-$ сила тока, $t$ - продолжительность электролиза, $A_{H_{2}}-$ выход по току водорода. Значения энергий образования и разрыва химических связей веществ находятся из таблиц [19].

Примем во внимание, что все электрохимические реакции протекают в двойном электрическом слое, а времена релаксации ионов могут быть определены по формуле [10]:

$$
\Theta=\frac{0,553}{C} \cdot 10^{-10} \quad c
$$

где $C$ - концентрация в г/ион л данного компонента в растворе, а время образования или разрушения ионной сферы составляет $10^{-7}-10^{-5} \mathrm{c}$.

Таким образом, можно предполагать, что все тепловые источники, за исключением диссипационных (теплоты Джоуля), локализованы в зонах электродных реакций или на незначительных удалениях от электродов.

Технологии создания энергоемких источников для летательных аппаратов

Вариант идеального накопителя можно представить следующей моделью, которая изображена на рис. 4.

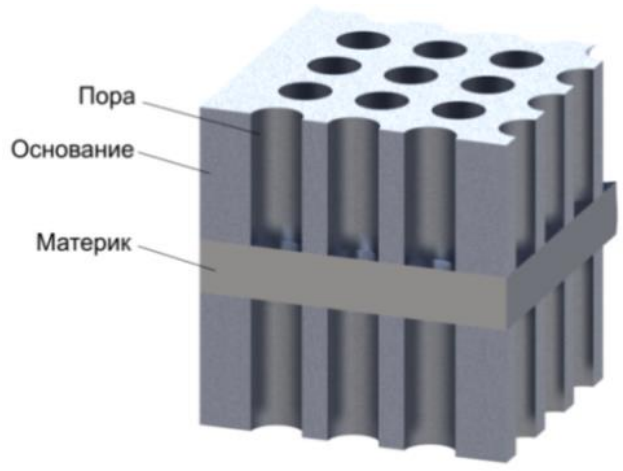

a

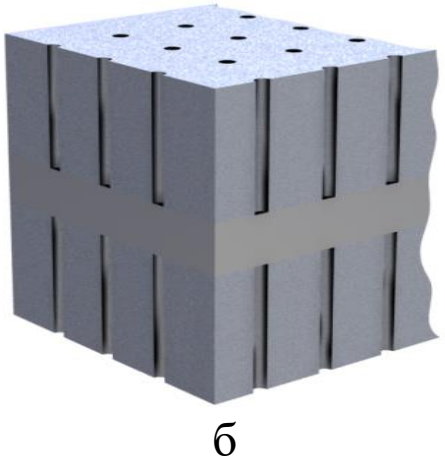

Рис. 4. Морфология структуры электрода водородного аккумулятора для разных режимов работы: а) режим больших токов и короткого времени использования б) режим малых токов и большего времени использования

Fig. 4. Morphology of the hydrogen battery electrode structure for different operating modes: a) a regime of high currents and a short time of use 6 ) the regime of low currents and longer use time

Такое представление электродной системы обеспечивает равнодоступность раствора к любым участкам электрода. Рассматривая вариант гидрида алюминия, следует отметить, что наиболее вероятное взаимодействие водорода с алюминием осуществляется по дефектам структуры. А наиболее близким аналогом технологии формирования электрода водородного аккумулятора является процесс анодной обработки алюминиевой фольги в производстве электролитических конденсаторов. 
Движущей силой для перемещения ионов водорода является тепловое поле, возникающее на границе раздела при гидратации иона $A l^{3+}$, при этом тепловой эффект данной реакции составляет 1122 ккал/моль [20].

Анализ известных технологий формирования электродных систем для аккумулирования, а также многочисленных теорий формообразования позволил сделать весьма важный вывод об аналогии структур идеализированного электрода с природными структурами, например, корневой системой растений (бионика).

Накопитель должен соответствовать следующим требованиям: отсутствие реакций взрывного характера и возможность регулирования скорости подачи топлива. Помимо главного преимущества (использование всего объема накопителя) одновременно реализуется эффект редукции. Физика этого явления объясняется различием времени транспорта водорода от условной точки нахождения гидрида до стенки поры

$$
\langle T\rangle=\frac{1}{N} \sum_{i=1}^{N} \frac{l_{i}}{V_{d i}}
$$

$\langle T\rangle-$ среднее время экстракции, $N$ - число частиц, $l$ - длина пробега частицы в процессе экстракции, $V_{\mathrm{d}}$ - скорость диффузии.

Даже при равенстве скоростей диффузии вероятность одновременного появления двух частиц пренебрежимо мала. Процесс экстракции растянут во времени. Редукционный эффект усиливается и за счет реализации в проходных сечениях пор газодинамического дросселирования за счет газодинамического сопротивления.

В промышленном способе получения гидрида ширина запрещенной зоны значительно больше и передача энергии осуществляется только за счет диффузии. Поэтому выделение энергии разнесено во времени (т.е. фактически тот же самый редукционный эффект). В реальном сплаве на основе алюминия также формируются структуры с разрывами колец и другой искаженной стехиометрией. Поэтому значения объемов накопления водорода для предельного типа накопителя может оказаться в пределах 15-20\%.

\section{ЛИТЕРАТ УР А}

1. Ватажин А.Б., Гуськов О.В., Данилов М.К., Копченов В.И. Генерация электроэнергии магнитогазодинамическим способом в моделях летательных аппаратов с высокоскоростным воздушно-реактивным двигателем. Изв. РАН. Meханика жидкости и газа. 2009. № 4. С. 153-161.
Весовые характеристики водородного накопителя соответствуют основным требованиям, предъявляемым к элементам конструкций летательных аппаратов, и обеспечивают необходимые скоростные режимы, дальность и длительность полета, следовательно, создаются предпосылки для их реализации в серийном промышленном производстве. Таким образом, данное направление может обеспечить значительный скачок в развитии новых технологий в авиации и в целом в энергетике народного хозяйства [21].

\section{ВЫВОДЫ}

В работе показана необходимость учета химического состава электролита, а также сопряженных процессов на электродах, которые вносят свой вклад в кинетику взаимодействия разряжающихся частиц на поверхности электродов. Тепловые эффекты на электродах являются определяющим фактором кинетики электрохимических и химических процессов. Показано, что для систем аккумулирования водорода главное предпочтение может быть отдано алюминию и сплавам на его основе, как наиболее доступному с точки зрения распространенности и наиболее приспособленному к масштабам промышленного производства. Дополнительным преимуществом накопителей данного типа является отсутствие требований к избыточному давлению, так как водород хранится без давления.

Предложенный новый физический принцип, связанный с переходом к технологиям 3D хранения водорода, фактически формирует новый класс летательных аппаратов - диапланы. Диаплан - класс летательных аппаратов, использующих водородное топливо в гидридной форме хранения (Два элемента: базовые компоненты водород+алюминий, Интеграция - гидрид как форма хранения, Альтернатива углеводородам, ПЛАНер).

Работа выполнена при финансовой поддержке Министерства образования и науки Российской Федераџии в рамках проектной части государственного задания № 9.11295.2018/10.11 "Разработка технологий высокоизносостойких покрытий подшипников скольжения со сверхмальмм коэффициентом трения на основе соединений $\mathrm{Ni}-\mathrm{B}^{\prime \prime}$.

\section{REFERENCES}

1. Vatazhin A.B., Guskov O.V., Danilov M.K., Kopchenov V.I. Electricity generation by magnetic-gasdynamic method in models of aircraft with high-speed air-jet engine. $I z v$. RAN. Mekhanika Zhidkosti i Gaza. 2009. N 4. P. 153-161 (in Russian). 
2. Крылов Ю.Е., Каминский В.Ю. Эффективность водородной транспортной энергетики. В сб.: Технологии построения когнитивных транспортных систем Материалы всероссийской научно-практической конференции. Ин-т проблем транспорта им. Н.С. Соломенко РАН. 2018. C. 193-197.

3. Черемных О.Я. Совершенствование оборудования для хранения и транспортирования жидкого водорода. Технич. газы. 2010. № 4. С. 44-52.

4. Klebanoff L.E., Pratt J.W., LaFleur C.B. Comparison of the safety-related physical and combustion properties of liquid hydrogen and liquid natural gas in the context of the sf-breeze high-speed fuel-cell ferry. Internat. J. Hydrogen Energy. 2017. V. 42. N 1. P. 757-774.

5. Дуников Д.О. Водородные энергетические технологии. Матер. семинара лаб. ВЭТ ОИВТ РАН: сб. науч. тр. М.: ОИВТ РАН. 2017. Вып. 1. 190 с.

6. Huang S.-J., Fang C., Rajagopal V., Chen Y.-L. Effect of different processes on hydrogen storage properties of az magnesium alloy. Mater. Sci. Forum. 2018. V. 920 MSF. P. 230-235.

7. Соловей В.В., Литвинов В.А. Термодинамические и технологические аспекты металлогидридной активации водорода. Технич. газы. 2013. № 3. С. 55-59.

8. Nakagawa Y., Lee C.-H., Matsui K., Kousaka K., Isobe S., Hashimoto N., Yamaguchi S., Miyaoka H., Kojima Y., Ichikawa T. Doping effect of nb species on hydrogen desorption properties of $\mathrm{AlH}_{3}$. J. Alloy. Comp. 2018. V. 734. P. 55-59.

9. Чертко Н.К., Чертко Э.Н. Геохимия и экология химических элементов. Минск: Издат. центр БГУ. 2008. 140 с.

10. Шалимов Ю.Н., Парфенюк В.И., Литвинов Ю.В., Кудряш В.И., Харченко Е.Л., Гаврилова Н.В., Шалимов Д.Л., Миленина Е.С. Процессы взаимодействия водорода с металлами в электрохимических системах. Изв. вузов. Химия и хим. технология. 2009. Т. 52. Вып. 5. C. 62-66.

11. Шалимов Ю.Н., Кудряш В.И., Гусев А.Л., Парфенюк В.И., Литвинов Ю.В., Сычев А.М., Харченко Е.Л., Шалимов Д.Л., Гаврилова Н.В., Миленина Е.С., Савельева Е.Л. Проблемы применения водорода в энергетике. Междун. науч. журн. Альтернатив. энергетика и экология. 2009. № 3 (71). С. 61-74.

12. Шалимов Ю.Н., Сатаров В.В., Подвальный С.Л., Филинов В.Г. Теплообменные процессы на электродах при импульсных режимах электроосаждения металлов. Докл. науч.-технич. рег. конф. Нестационарные электрохимические процессы. Барнаул. 1990. С. 50-62.

13. Дикусар А.И., Энгельгардт Г.Р., Молин А.Н. Термокинетические явления при высокоскоростных электродных процессах. Кишинев: Штиница. 1989. 218 с.

14. Шалимов Ю.Н., Звягинцева А.В., Шалимов Д.Л., Pуссу А.В. Об особенностях воздействия температуры приэлектродного слоя на процессы получения электролитических металлов и сплавов. Вестн. Воронеж. гос. технич. ун-та. 2018. Т. 14. № 3. С. 141-149.

15. Брысенкова Н.В., Шалимов Ю.Н., Парфенюк В.И. Накопители водорода на основе гидридов никеля и алюминия. Изв. вузов. Химия и хим. технология. 2011. Т. 54. Вып. 11. С. 131-135.

16. Шалимов Ю.Н., Лутовац М., Руссу А.В., Адианов И.В. Водородные технологии, повышающие надежность летательных аппаратов различных типов, применяемых в условиях чрезвычайных ситуаций. Вестн. Воронеж. ин-та ГПС МЧС России. 2016. № 4 (21). С. 98-101.
2. Krylov Yu.E., Kaminsky V.Yu. The efficiency of hydrogen transport energy. In Proc .: Technologies for the construction of cognitive transport systems Materials of the All-Russian scientific-practical conference. FGBUN Institute of Transport Problems. N.S. Solomenko of the Russian Academy of Sciences. 2018. P. 193-197 (in Russian).

3. Cheremnykh O.Ya. Improving equipment for the storage and transportation of liquid hydrogen. Tekhnich. Gazy. 2010. N 4. P. 44-52 (in Russian).

4. Klebanoff L.E., Pratt J.W., LaFleur C.B. Comparison of the safety-related physical and combustion properties of liquid hydrogen and liquid natural gas in the context of the sf-breeze high-speed fuel-cell ferry. Internat. J. Hydrogen Energy. 2017. V. 42. N 1. P. 757-774.

5. Dunikov D.O. Hydrogen energy technology. Proceedings of the workshop of the laboratory VET JIHT RAS: Sat. scientific tr. M .: JIHT RAS. 2017. V. 1. 190 p. (in Russian).

6. Huang S.-J., Fang C., Rajagopal V., Chen Y.-L. Effect of different processes on hydrogen storage properties of az magnesium alloy. Mater. Sci. Forum. 2018. V. 920 MSF. P. 230-235.

7. Solovey V.V., Litvinov V.A. Thermodynamic and technological aspects of metal hydride activation of hydrogen. Tekhnich. Gazy. 2013. N 3. P. 55-59 (in Russian).

8. Nakagawa Y., Lee C.-H., Matsui K., Kousaka K., Isobe S., Hashimoto N., Yamaguchi S., Miyaoka H., Kojima Y., Ichikawa T. Doping effect of nb species on hydrogen desorption properties of $\mathrm{AlH}_{3}$. J. Alloy. Comp. 2018. V. 734. P. 55-59.

9. Chertko N.K., Chertko E.N. Geochemistry and ecology of chemical elements. Minsk: Publishing Center of BSU. 2008. 140 p. (in Russian).

10. Shalimov Yu.N., Parfenyuk V.I., Litvinov Yu.V., Kudryash V.I., Kharchenko E.L., Gavrilova N.V., Shalimov D.L., Milenina E.S. The processes of interaction of hydrogen with metals in electrochemical systems. Izv. Vyssh. Uchebn. Zaved. Khim. Khim. Tekhnol. 2009. V. 52. N 5. P. $62-66$ (in Russian).

11. Shalimov Yu.N., Kudryash V.I., Gusev A.L., Parfenyuk V.I., Litvinov Yu.V., Sychev A.M., Kharchenko E.L., Shalimov D.L., Gavrilova N.V., Milenina E.S., Savelieva E.L. Problems of hydrogen application in the energy. Internat. J. Alternative Energy and Ecology. 2009. N 3 (71). P. 61-74 (in Russian).

12. Shalimov Yu.N., Satarov V.V., Podvalny S.L., Filinov V.G. Heat exchange processes on the electrodes during pulsed modes of electrodeposition of metals. Report scientific and technical regional conference. Non-stationary electrochemical processes. Barnaul. 1990. P. 50-62 (in Russian).

13. Dikusar A.I., Engelhardt G.R., Molin A.N. Thermokinetic phenomena in high-speed electrode processes. Chisinau: Stinitsa. 1989. 218 p. (in Russian).

14. Shalimov Yu.N., Zvyagintseva AV, Shalimov D.L., Russu A.V. On the peculiarities of the effect of the temperature of the near-electrode layer on the processes of obtaining electrolytic metals and alloys. Vestn. Voronezh. Gos. Tekhnich. Un-ta. 2018. V. 14. N 3. P. 141-149 (in Russian).

15. Brysenkova N.V., Shalimov Yu.N., Parfenyuk V.I. Hydrogen storage tanks based on nickel and aluminum hydrides. Izv. Vyssh. Uchebn. Zaved. Khim. Khim. Tekhnol. 2011. V. 54. N 11. P. 131-135 (in Russian). 
17. Шалимов Ю.Н., Кудряш В.И., Руссу А.В. Аккумуляторы водорода с высокоэффективной системой накопления. В сб.: Современные методы прикладной математики, теории управления и компьютерных технологий (ПМТУКТ-2016). Сб. тр. IX международной конференции. Воронеж. 2016. С. 393-395.

18. Бабкин В.Ф., Евсеев Е.П., Шалимов Ю.Н., Руссу А.В., Кудряш В.И. Перспективы развития водородной энергетики. Пожар. безопас.: пробл. и персп. 2016. Т. 2. № 1 (7). C. 232-237.

19. Веденеев В.И., Гурвич Л.В., Кондратьев В.Н., Медведев В.А., Франкевич Е.Л. Энергия разрыва химических связей. Потенциалы ионизации и сродство к электрону. М.: Академия наук СССР. 1962. 215с.

20. Колодяжный С.А., Ступин В.И., Шалимов Ю.Н., Лутовац М., Войтович Д., Мирянич Д., Кудряш В.И., Звягинцева А.В., Руссу А.В. Аккумуляторы водорода с высокоэффективной системой накопления. В сб.: Комплексные проблемы техносферной безопасности Воронежский государственный технический университет. 2016. C. 192-195.

21. Ратнер С.В. Инновации в авиастроении: анализ результатов исследовательских программ по разработке альтернативных видов авиационного топлива. Национал. интересы: приоритеты и безопасность. 2018. Т. 14. № 3 (360). C. $492-506$.
16. Shalimov Yu.N., Lutovats M., Russu A.V., Adianov I.V. Hydrogen technologies that increase the reliability of various types of aircraft used in emergency situations. Vest. Voronezh Institute of the State Fire Service of the Emercom of Russia. 2016. N 4 (21). P. 98-101 (in Russian).

17. Shalimov Yu.N., Kudryash V.I., Russu A.V. Hydrogen accumulators with a highly efficient accumulation system. In Proc .: Modern methods of applied mathematics, control theory and computer technology (PMTUKT-2016) Sb. tr. IX International Conference. Voronezh. 2016. P. 393-395 (in Russian).

18. Babkin V.F., Evseev E.P., Shalimov Yu.N., Russu A.V., Kudryash V.I. Prospects for the development of hydrogen energy. Pozharn. Bezopas.: Probl. i Perspect. 2016. V. 2. N 1 (7). P. 232-237 (in Russian).

19. Vedeneev V.I., Gurvich L.V., Kondratiev V.N., Medvedev V.A., Frankevich E.L. The energy of breaking chemical bonds. Ionization potentials and electron affinity. M.: Academy of Sciences of the USSR. 1962. 215 p. (in Russian).

20. Kolodyazhny S.A., Stupin V.I., Shalimov Yu.N., Lutovats M., Voitovich D., Mirayanich D., Kudryash V.I., Zvyagintseva A.V., Russu A.V. Hydrogen accumulators with a highly efficient accumulation system. In Proc.: Complex problems of technospheric safety. Voronezh State Technical University. 2016. P. 192-195 (in Russian).

21. Ratner S.V. Innovations in aircraft industry: analysis of the results of research programs for the development of alternative types of aviation fuel. Natsional. Interesy: Prioritety $i$ Bezopasnost'. 2018. V. 14. N 3 (360). P. $492-506$ (in Russian).

Поступила в редакцию 04.04.2018

Принята к опубликованию 30.10.2018

Received 04.04.2018

Accepted 30.10.2018 